\title{
HEAT TRANSFER LABORATORY OF THE SAVANNAH RIVER LABORATORY
}

D. H. KNOEBEL

S. D. HARRIS
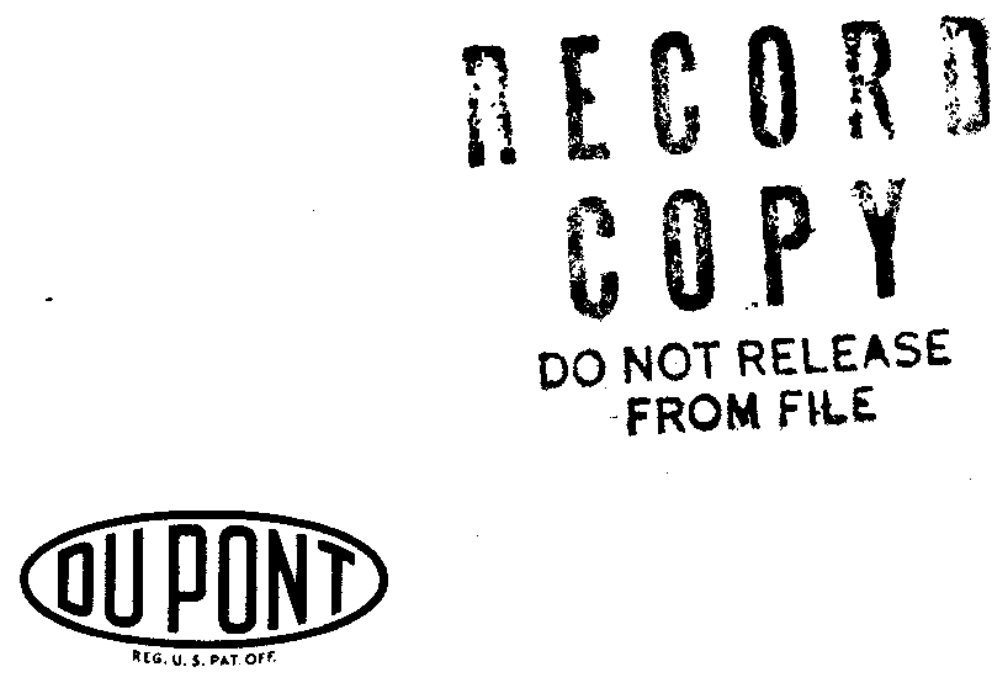

E. I. du Pont de Nemours \& Co. Savannah River Laboratory Aiken, S. C. 29801

PREPARED FOR THE U. S. ATOMIC ENERGY COMMISSION UNDER CONTRACT AT(07-2)-1 


\section{NOTICE}

This report was prepared as an account of work sponsored by the United States Government. Neither the United States nor the United States Atomic Energy Commission, nor any, of their employees, nor any of their contractors, subcontractors, or their employees, makes any warranty, express or implied, or assumes any legal liability or responsibility for the accuracy, completeness or usefulness of any information, apparatus, product or process disclosed, or represents that its use would not infringe privately owned rights.

Printed in the United States of America Available from

National Technical Information Service

U. S. Department of Commerce

5285 Port Royal Road

Springfield, Virginia 22151

Price: Printed Copy $\$ 4.00$; Microfiche $\$ 0.95$ 
Engineering and Equipment

TID-4500-R60, UC-38

662846

\section{HEAT TRANSFER LABORATORY OF THE SAVANNAH RIVER LABORATORY}

by

D. H. Knoebel

S. D. Harris

Approved by

J. M. Boswe11, Research Manager

Reactor Engineering Division

Publication Date: October 1973

E. I. du Pont de Nemours \& Co. Savannah River Laboratory

Aiken, S. C. 29801

PREPARED FOR THE U. S. ATOMIC ENERGY COMMISSION UNDER CONTRACT AT(07-2)-1 


\begin{abstract}
The Heat Transfer Laboratory, recently constructed adjacent to the main Savannah River Laboratory building, was designed to mock up nuclear heating and cooling of reactor components under a variety of conditions. Nuclear heating is simulated by electrical resistance heating of test sections with a 3 MW directcurrent power supply. Cooling is provided by water. Three test stations (A, B, and C) are available for testing full-size fuel assemblies, measuring flow instabilities, and for measuring burnout heat fluxes. Safeguards provided in the design of the facility and conservative operating procedures minimize or eliminate potential hazards.
\end{abstract}


CONTENTS

Page

Introduction . . . . . . . . . . . . . . . 5

Building . . . . . . . . . . . . . . . . . 5

Experimental Test Stations.............. 8

Test Station A . . . . . . . . . . . 10

Test Station B................. 12

Test Station C . . . . . . . . . . . . . 14

Power Supply . . . . . . . . . . . . . . . . 15

Rectifier Units . . . . . . . . . . . . 15

Rectifier Controls . . . . . . . . . . . . . 17

Cooling Water System . . . . . . . . . . . . 18

Instrumentation ... . . . . . . . . . . . . 21

Supporting Services . . . . . . . . . . . . . 24

Safety . . . . . . . . . . . . . . . . . 24 


\section{LIST OF FIGURES}

Page

1. Heat Transfer Laboratory Building . . . . . . . 6

2. Floor Plan of Laboratory .. . . . . . . 7

3. Equipment Layout . . . . . . . . . . . 9

4. Test Station A Plan . . . . . . . . . . . . . . 11

5. Test Station A . . . . . . . . . . . . . 12

6. Test Station B with Test Rig in Place... . . . 13

7. Test Station $\mathrm{C}$ with Test Rig in Place... . . . . 14

8. Rectifier Units . . . . . . . . . . . 15

9. Schematic of Rectifier Circuit . . ... . . 16

10. Cross Section of Bus Bars ............ 17

11. Process Piping Schematic ........... 19

12. Schematic of Piping to a Single Station . . . . 20

13. Control Console . . . . . . . . . . . 22

14. Recorder Console .............. 23 
HEAT TRANSFER LABORATORY

OF THE SAVANNAH RIVER LABORATORY

\section{INTRODUCTION}

Several heat transfer laboratories using large DC power supplies and low or high pressure hydraulic loops are in operation in Europe and the Western Hemisphere. Three prominent ones are at Columbia University ( $8 \mathrm{MW}$ motor generator supply), Battelle Memorial Institute Pacific Northwest Laboratory (1.5 MW rectifier supply and a $3 \mathrm{MW}$ motor-generator supply), and Studsuik Research Establishment in Sweden ( $8 \mathrm{MW}$ rectifier supp1y). Previously, the Savannah River Laboratory had a 0.32 MW motorgenerator supply and contracted work requiring higher power to Columbia University.

To maintain the necessary high degree of safety in the more complex modes of Savannah River Plant (SRP) reactor operation, the capability of test facilities onsite needed to be expanded to permit experimental investigations associated with flow instability, reactor fuel design, loss-of-target accidents, metalwater corrosion and erosion, and cooling effectiveness during transient conditions. The new Heat Transfer Laboratory was designed to provide these capabilities. The laboratory is located adjacent to the Main Laboratory Building.

\section{BUILDING}

The Heat Transfer Laboratory (Figure 1) and the adjoining electrical substation are prefabricated steel buildings erected on concrete slabs. The substation building contains dry type transformers available from Savannah River Plant excess. The laboratory building is 40 feet wide, 80 feet 1 ong, and 24 feet high at the eaves. It is divided into an office area (20 feet long) and an experimental area (60 feet long). Figure 2 is a floor plan of the building. 


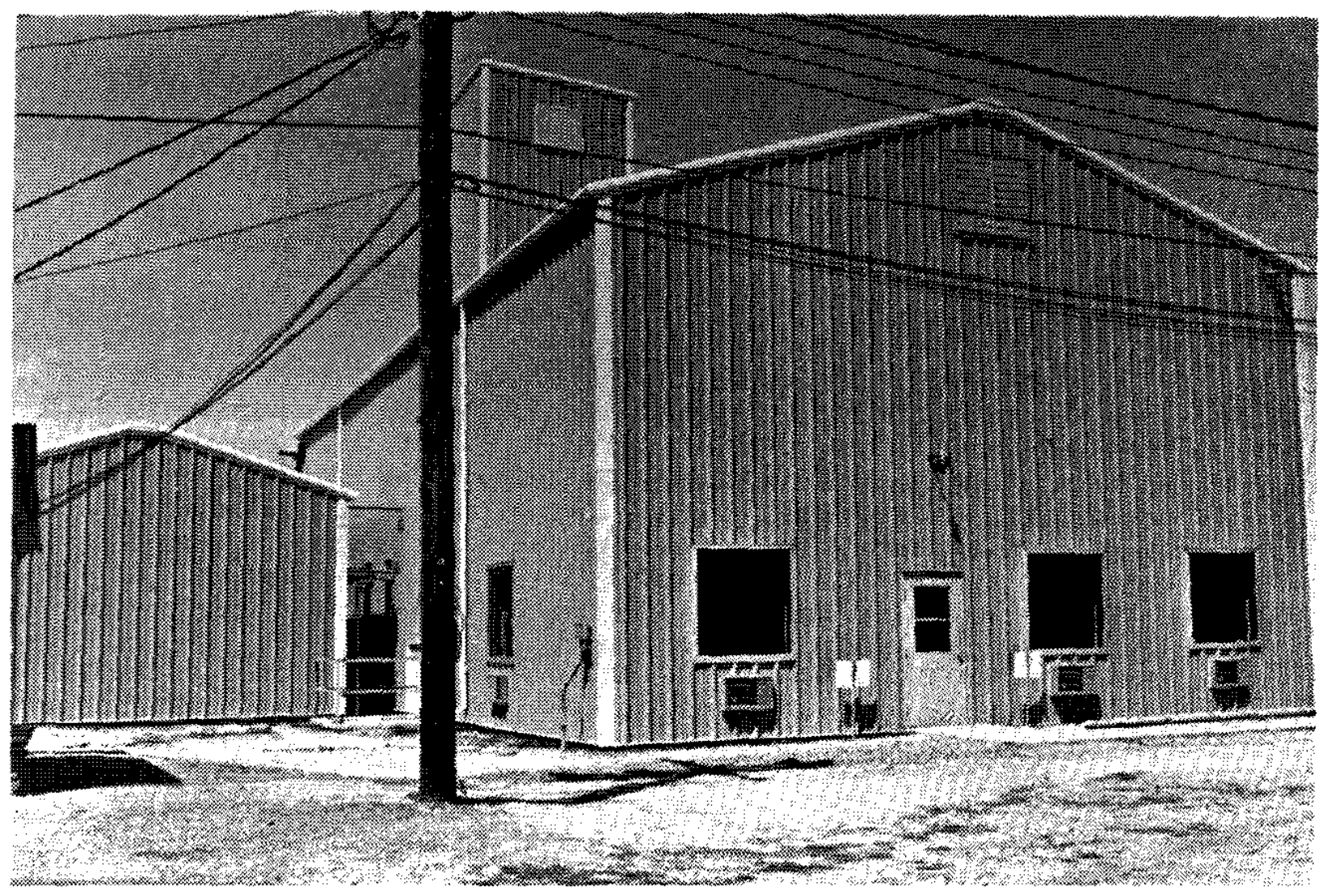

FIG. 1. HEAT TRANSFER LABORATORY BUILDING 


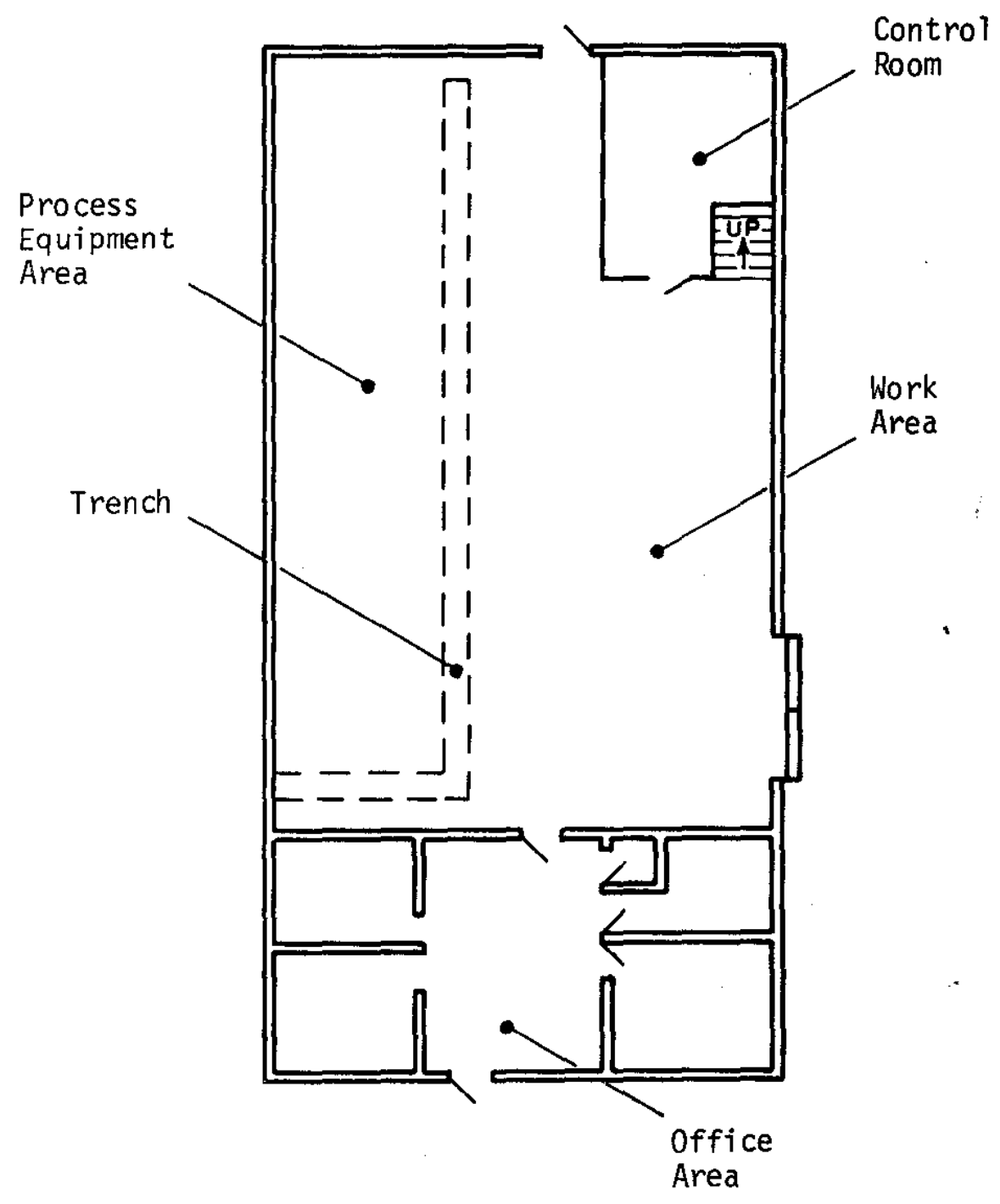

FIG. 2. FLOOR PLAN OF LABORATORY 
The experimental area contains all of the experimental equipment (rectifiers, pumps, heat exchangers, piping, test stations, and control console) and a work area for assembling test apparatus. A 12-foot by 12-foot by 57-foot-high loading tower is over one test station at the north end of the building. The tower contains a hoist (l ton capacity) for manipulating large test sections into the test station vessel. The control console contains all the motor, power, and valve controls and associated instrumentation. The console and instrument rack are in an air-conditioned enclosure for constant temperature and humidity control to protect sensitive instruments.

A covered trench in the floor runs the length of the experimental area at approximately the building center line. The trench leads to a sump outside the building along the west wall. The trench serves two purposes: drainage of spilled water to the sump, and concealment of piping and electrical conduits. The trench is designed to operate dry normally, but has the capacity to contain the total test loop water volume in the event of a spill.

\section{EXPERIMENTAL TEST STATIONS}

The laboratory is arranged around three experimental test stations (A, B, and $C$ in Figure 3 ) differing in capacity and purpose. The separate test stations provide for more-efficient use of power and flow equipment because test apparatus for one experiment does not need to be taken off line between tests to make way for tests with another apparatus for another study. Because time spent in setup and preparation for a test in considerably longer than the actual test time, sharing the power supply between stations is a negligible inconvenience.

The purpose of each of the three test stations is nominally as follows:

$$
\begin{aligned}
& \text { A - Full size assembly testing } \\
& \text { B - Assembly flow instability } \\
& \text { C - Burnout heat flux measurements. }
\end{aligned}
$$

These functions can be interchanged among the test stations depending upon flow conditions required and the test section size. 


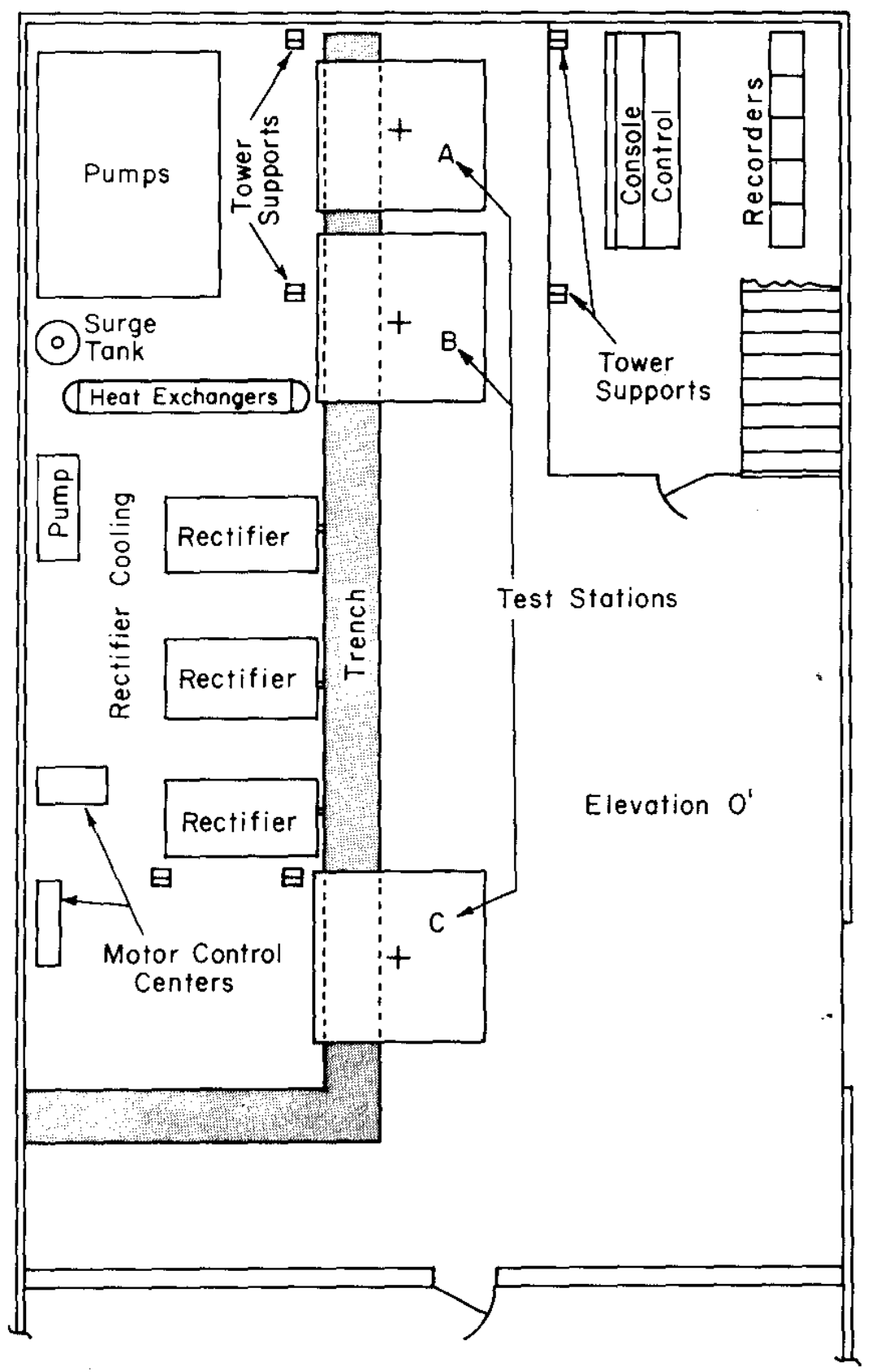

FIG. 3 EQUIPMENT LAYOUT 


\section{Test Station A}

Test Station A (Figures 4,5 ) is for full size assembly tests involving assembly flow instability, end-fitting response to twophase flow, steam injection into the moderator, and natural convection heat transfer in various types of reactor components. Test Station A is basically a tank, 3 feet in diameter, 20 feet high, capped by a pressurized inlet header (or plenum), and representing a mockup of a portion of an SRP reactor tank, with exact size plenum, permanent sleeves, and tank height. There are positions for 19 assemblies: 17 are "dummies" for a normal test, and two may be used for heated elements. The dummy positions can provide bypass flow around the test position to maintain an approximately constant hydraulic head across the test assembly.

Full pump flow (1200 gpm) can be supplied to the plenum. In addition, piping for a steam quench flow or secondary flow of up to $400 \mathrm{gpm}$ is provided for the tank. Flow may be returned to pump suction either from the top of the tank or the bottom, depending upon the external cooling conditions to be imposed on the test section. The tank level is controlled automatically with a pneumatic system that regulates the water level by controlling air pressure in the space between tank water surface and plenum bottom.

Power for heating test sections may be introduced at the top above the plenum, or through ports in the side of the tank near the top and bottom. Six observation windows are located at three levels. Personnel access ports are also located at three levels to assist installation of test sections and instrumentation.

The two positions for heated test sections are provided with flow monitor pins at the tank bottom identical to those in SRP reactors so that instrument readings similar to those observed in the reactor may be obtained. Provision is also made in the tank wall for attaching pressure and temperature leads to the test sections for detailed measurements. End fittings are attached to the discharge ends of the test sections to develop signals for flow and temperature monitoring.

\section{Test Station B}

Test Station B was designed to study internal assembly heat transfer and hydraulic characteristics, where the presence (and/or complication) of moderator cooling is not necessary. Typical testing includes flow instability, end-fitting characteristics, and multichannel hydraulic coupling with single phase and subcooled nucleate boiling flow. 


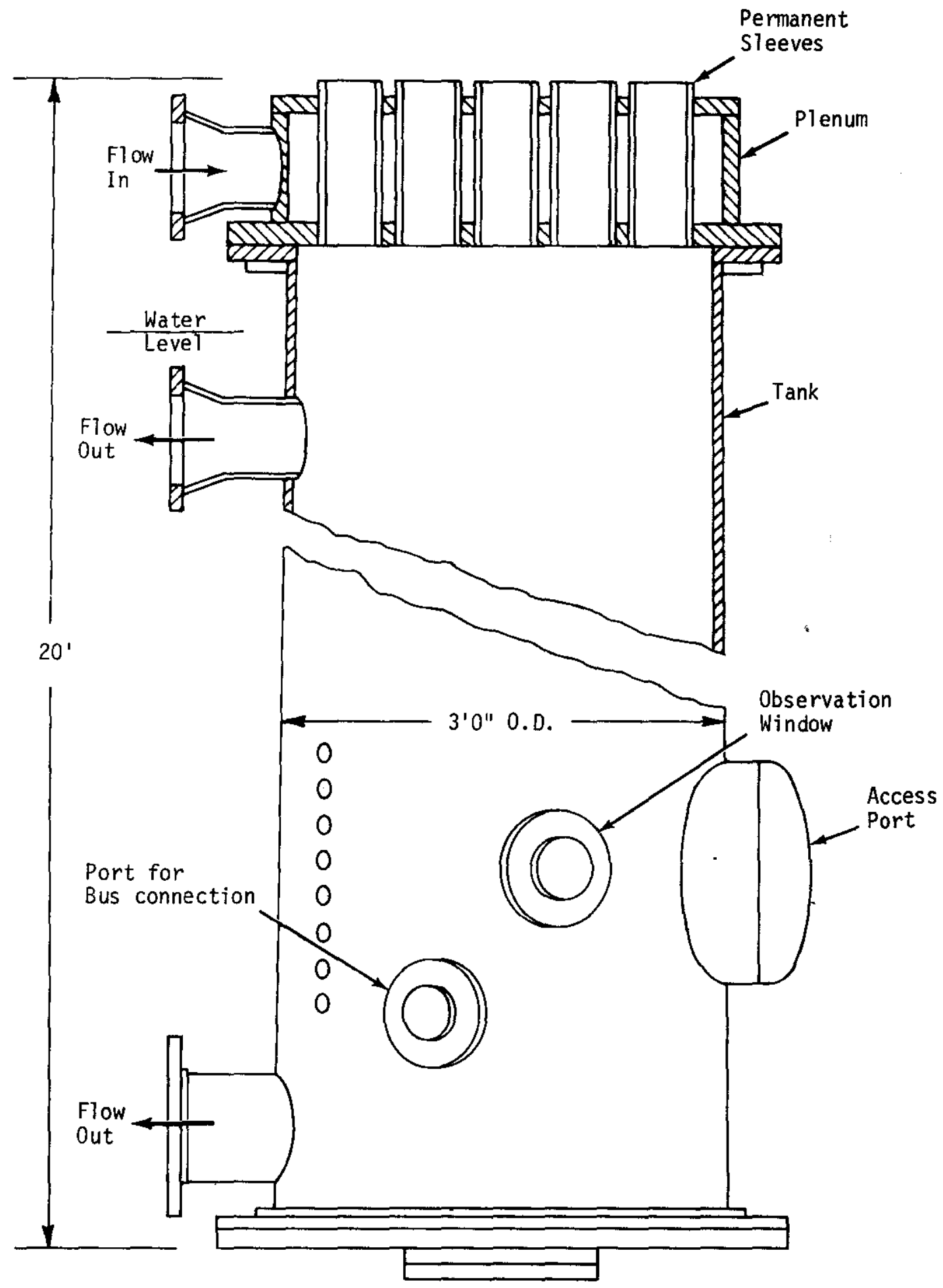

FIG. 4. TEST STATION A PLAN 


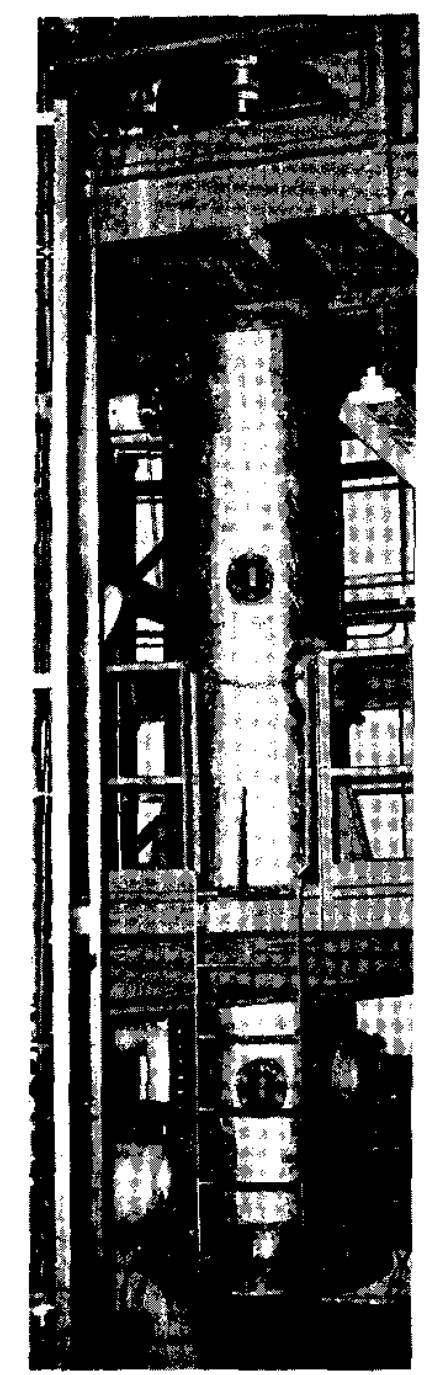

FIG. 5. TEST STATION A

Test Station B consists of a flanged inlet header located at elevation 23 feet and two return headers at the floor.

Connections to the DC power supply are available at elevation 17 feet and the floor. Maximum flow is $1200 \mathrm{gpm}$ at $220 \mathrm{psi}$ with up to $400 \mathrm{gpm}$ secondary or quench flow. Between the flanges of the inlet and return headers, test sections may be fitted that are limited only by the ingenuity of the experimenter. Figure 6 shows a typical test apparatus.

Instrumentation identical to that at Test Station A is available. Permanently installed pressure and thermocouple connections originating near test section inlet and return 
header flanges lad to transducers and signal conditioners in the control duclosure. Flow may be bypassed through permanent system bypass piping to mantain constant head, or as in the arrangenent shown in pigure 6 , bypass features may be inherent in the test avparatus.

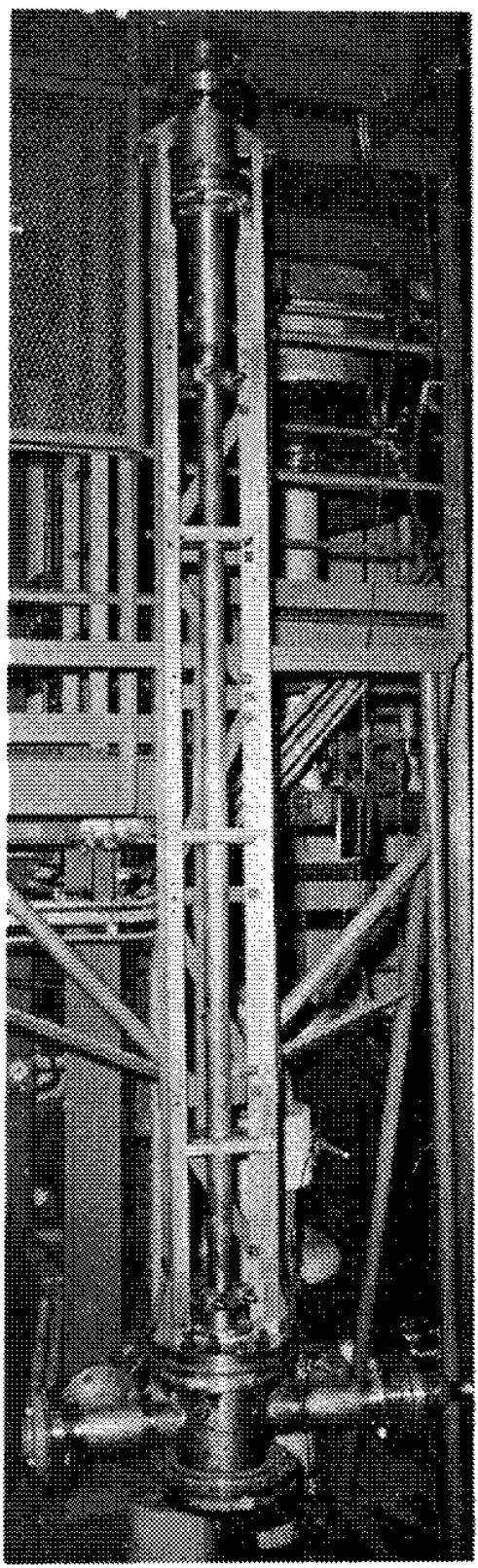

FIG. 6. TEST STATION B WTTH TEST RIG IN PLACE 


\section{Test Station $c$}

rest Station C as desigred primaxily for burnout studies, although it is not limited to bumout tests. Compared to Test Station $B$, maximun flow is less and the test section size is smaller. Like Test Station B, Test Station $C$ has the inlet and return process water flanges and the DC power bus connection points. Within the physical limits of the test station, any test section may be used. Figure 7 shows Test Station $C$ with a typal test section installed. Inlet headexs are 16.5 feet above the floor, and discharge headers are at the floor. Maximum flow is $400 \mathrm{gpm}$ at $220 \mathrm{psi}$, with $90 \mathrm{gpm}$ aval lable as a secondary or quench flow. Pressure and temperature connections leading back to the control enclosure are installed at top and bottom of the test section.

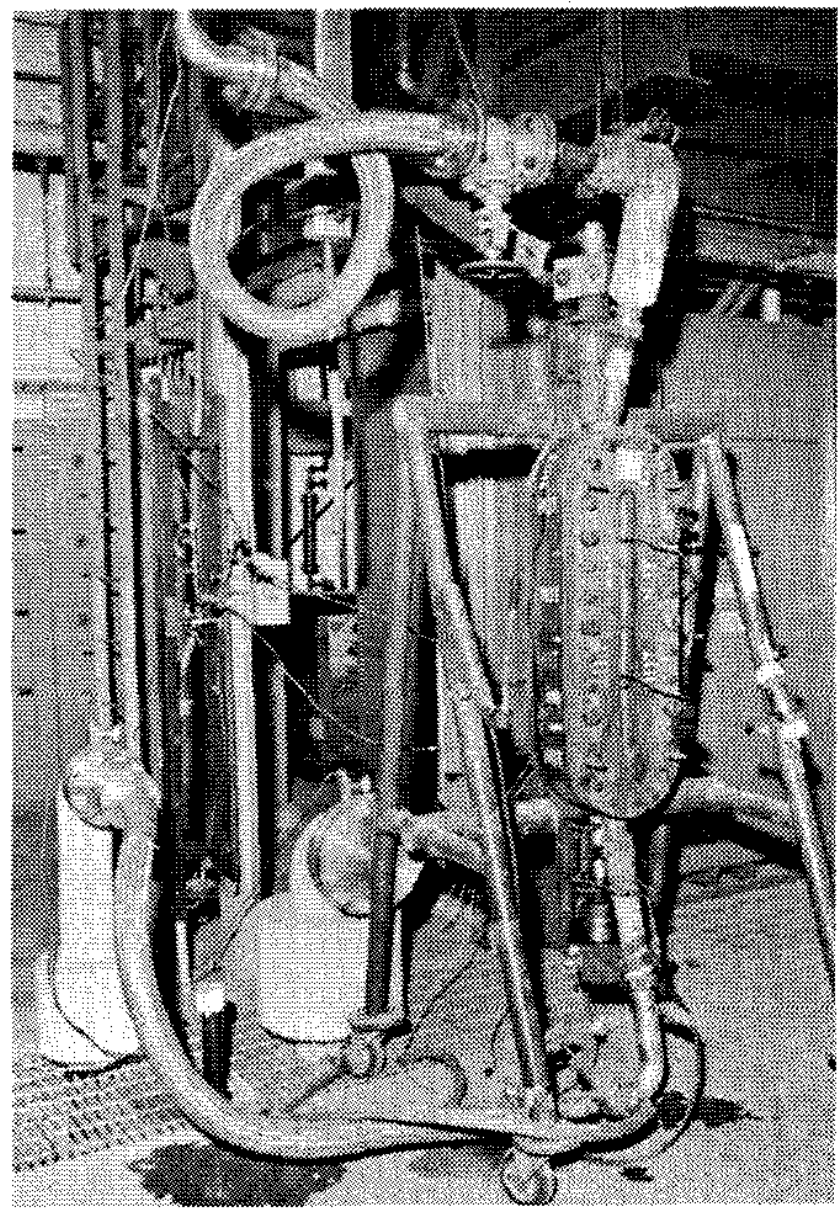

FIG. 7. TEST STATION C WITH TEST RIG IN PLACE 


\section{POWER SUPPIY}

Electrical power is provided to the Heat Transfer Laboratory from the adjacent substation. The substation contains three $1500 \mathrm{kva}$ sxustomers reducing line voltage from 13,800 volts to $460 \mathrm{vol}$. The 460 volt power is supplied to the rectifier units in the labotatory through overhead enclosed trays extending from the substation to the laboratory. Power for lights, pumps, instrumerats, and uthlities passes to the laboratory through wherground conduits to motox control centers, from which it is aistributed.

\section{Rectifier units}

Wrect current powew is provided by six large solid state restis ars connected in paxallel (Figure 8). Each unit has a maximum rated output of $0.5 \mathrm{MW} \mathrm{DC}$ at 5000 amperes. Total capacity is 3 WW DC with anits on line. Depending upon test conditions, one or more untes may be selected for use during a test.

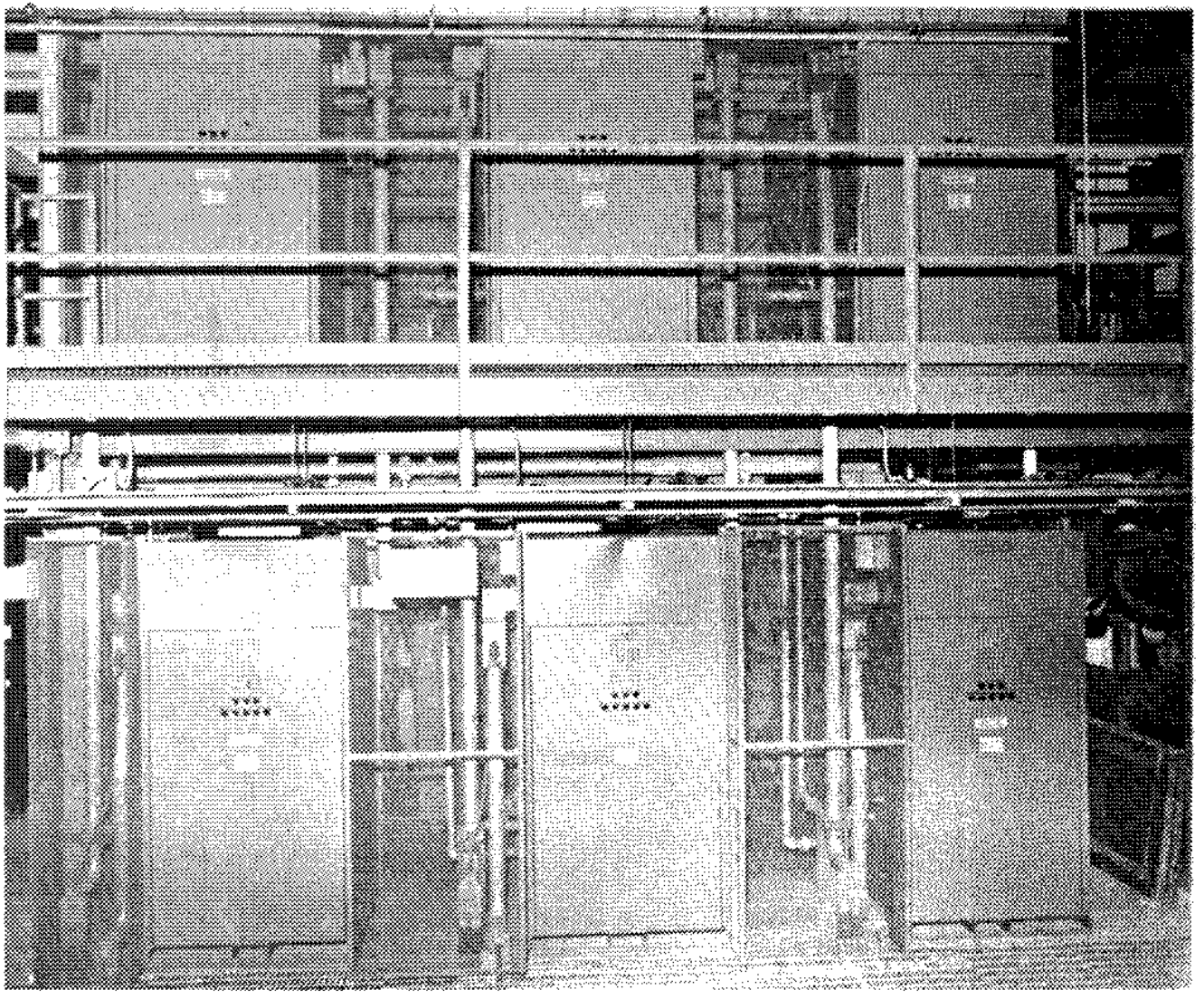

FIG. 8. RECTIFIER UNITS 
Figure 9 is a schematic of the rectification circuit. The wave shape of one phase at each stage is indicated. Three phase 460 volu AC power from the substation transformers first passes through silicon controlled rectifiers (SCR), which are used to control total power. After the SCR's, the current is still a temating and is stepped down to a lower voltage by transformers in the recticter cablnets. To minimize ripple, tapped transformers were us a to enchle pperation near peak voltage with test sections of vatious impedances. The transformer secondary may be tapped at 30,60 , or 120 volts. For example, if the resistance of a test section were such that 30 volts was rem gulred at 5000 ampere pperation, the waveform would be nearly pure DC it the 30 volt taps were used (i.e., ripple would be almost zero). However, if the 60 volt taps were used with the sane load at 5000 amp, the waveform would have a high percent ripple, causing the power generation in the test section to fluctuate at the power frequency $(360 \mathrm{~Hz}$ for three phase). Instmuentation, bubble formation, and other phenomena possibly critical to the experiment can be affected by this oscillating power.

Power is collected and distributed by bus bars made from $4 \times 4 \times 3 / 4$ inch aluminum channel (Figure 10). The busses run the length of the experimental area: the positive bus is at 17 feet; the negative bus is in the trench. Connection blocks are provided for attachment of flexible connectors at each test station. Bus cooling is provided by water flowing through the canter of the bus.

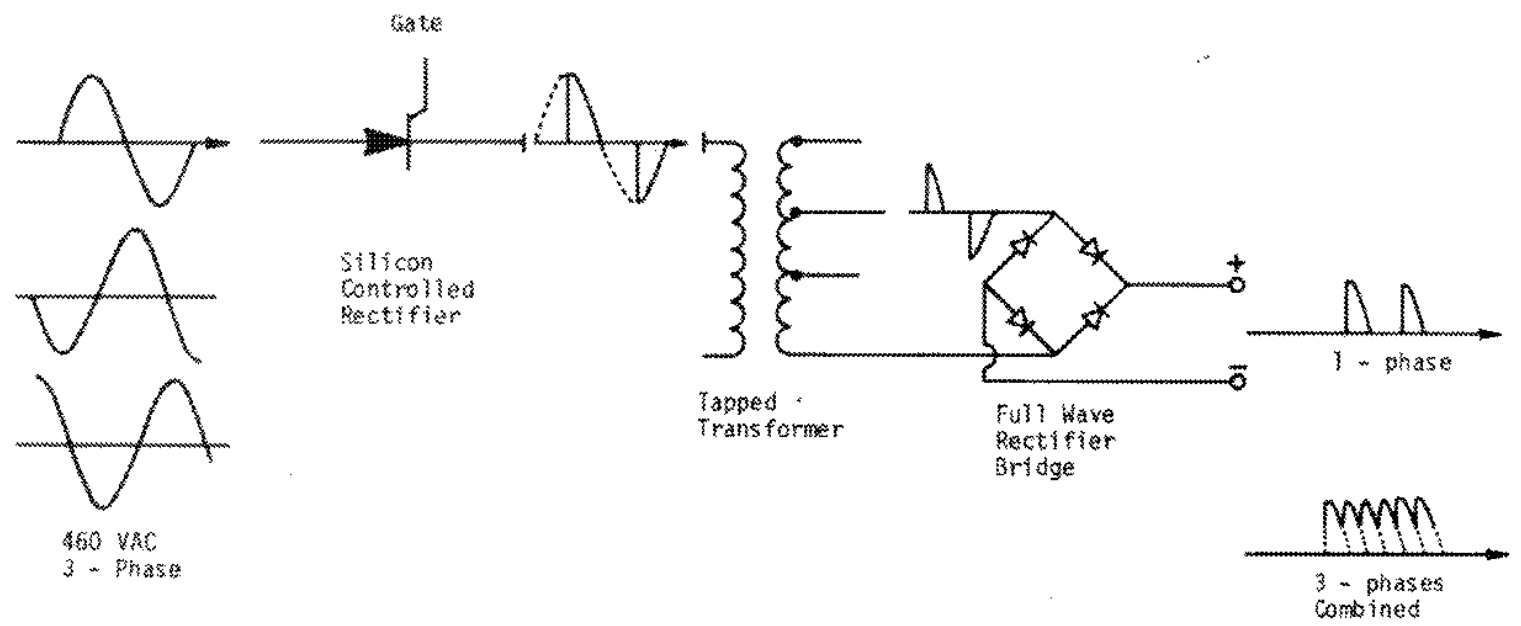

FIG. 9. SCHEMATIC OF RECTIFIER CIRCUIT 

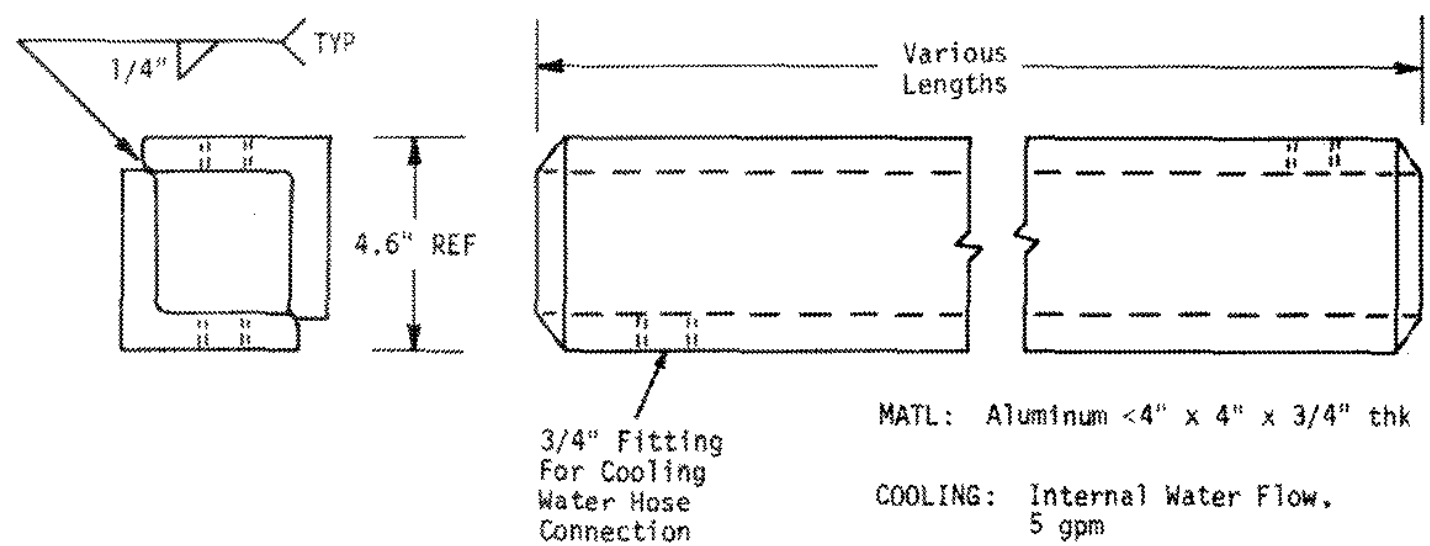

Fla. 10. CROSS SECTYN OF BUS BARS

Connections are wade to a test section by water-cooled flexyble busses extending from the busses to copper adapter blocks appropriate fox each tesc section. Cooling for the flexible connecting busses is provided from the bus cooling system.

Ned ther the positive nor negative bus is connected to the bulding electrical ground. This "floating" system was specificd cot the protection afforded persomel and equipment from an electrical shore at high current. An apparatus may becone grounded at one place to building ground (for example by contacting process water piping or rig framework) without a bamagng axc because these is no path back to the second bus until a second ground occurs. Operating procedures prohibit startup wh a gromded apparatus. A ground detection device alerts operators and shuts of the power when a ground occurs duran a test. The necessity for two separate grounds before an are or a shock hazard can exist enhances the system safety.

\section{Rectifier Controls}

The rectifers are mont tored and operated from the control consoly. Rectifier units to be used are selected by appropriate switches. The output of the combined rectifiers is controlled by angle master control potentiometer. Power can be started and stopyed wh single start and stop buttons. At a given setting, the rectifiers hold the setpoint by internal feedback of voltage or current, the control variable being chosen by the operatox. pectifier powe may also be programmed to follow any power-versus time curve by feeding in an externally generated voltage signal describing the destred curve. This option can be used to simulate reactor power during postulated transients. 
Each rectifiex has an individual shumt for monitoring $D C$ current. A voltmeter connected internally monitors the output voluge. Experimental power data is obtained with a specially constructed wattmeter which integrates the product of current and voltage, including any ripple, to obtain the exact DC heating value. Total current is obtained with a special measuring head sensiture to the magnetic field produced by the bus. Voltage is obtained by taps at top and bottom of the heated section. Voltage, current, and power are displayed by digital meters on the master control panel for quick reference. Power is also recorded on a chart recorder for permanent records. Accuracy of the power measurement is rated at $0.1 \%$ of the meter range selected. Metex ranges span from 0.3 to $3.6 \mathrm{MN}$ in 6 intervals.

\section{COOLING WATER SYSTEM}

A detalled schematic of the process water flow loops is shown in figure 11. The intent of the design is to provide the three test stations with a choice of cooling supply:

\begin{tabular}{ccc} 
Max. Pumping Rate & Pipe Diam. in. & $\frac{\text { Test Station }}{1200 \mathrm{gpm}}$ \\
\hline $200 \mathrm{gpm}$ & 6 & $\mathrm{~A}, \mathrm{~B}$ \\
$400 \mathrm{gpm}$ & 3 & $\mathrm{~A}, \mathrm{~B}$ \\
$170 \mathrm{gpm}$ & 1.5 & $\mathrm{~A}, \mathrm{~B}, \mathrm{C}$ \\
& 2 & $\mathrm{~A}, \mathrm{~B}, \mathrm{C}$ (Quench Flow)
\end{tabular}

Within these limits considerable latitude is possible, so that many combinations of primary coolant flow, quench or secondary flow, and test section pressure are possible at each station. Installed equipment includes:

Trree $400-$ gpm pumps at $400 \mathrm{ft} \mathrm{H}_{2} \mathrm{O}$ head
One $\quad 90-$ gpm pump at $200 \mathrm{ft} \mathrm{H}_{2} \mathrm{O}$ head
One $\quad 1000-\mathrm{gal}$ calibration tank
One $\quad 200-\mathrm{ga} 1$ surge tank
One $\quad 20-\mathrm{gal}$ surge tank
Two $\quad 600-\mathrm{ft}^{2}$ heat excahngers
One $\quad 300-\mathrm{ft}^{2}$ heat exchanger
Two $\quad 20-\mathrm{gpm}$ deionizers
Control valves for pressure, tenperature, and flow control
Interconnecting piping

A11 process piping valves and tanks are stainless steel. The process cooling watex header is galvanized steel pipe. 


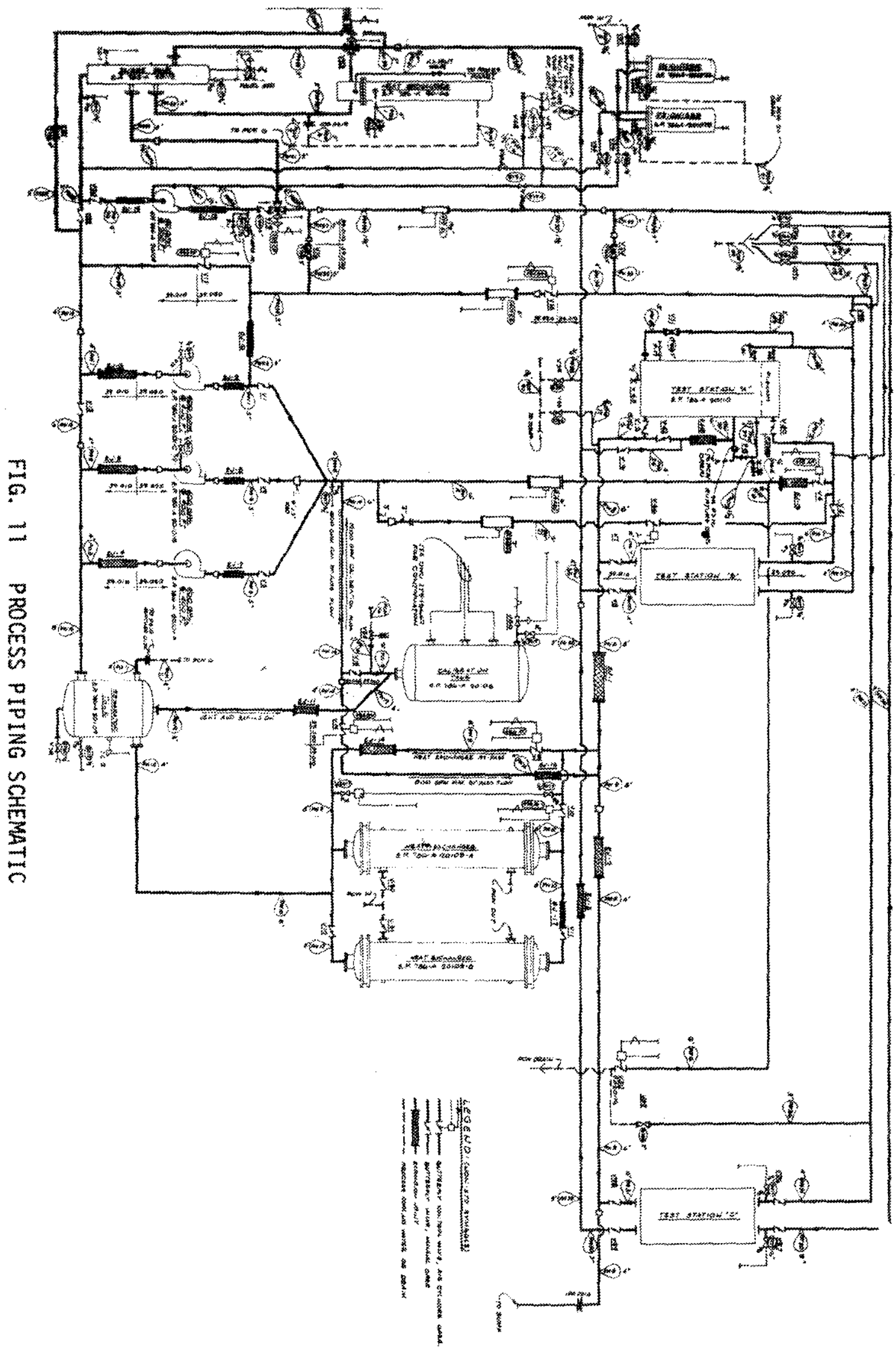


For clarity, figure 12 is presented to illustrate cooling supply only to rest station $B$. By apprporiate valving, the other stations can be supplied in a similar manner. In Figure 12, arinary coolant is supplied by one or more of the 400 gpm pumps in parallel. Inlet pressure and flow are adjusted by upstream valying and/ox bypassing a part of the pump flow through a bypass Iine. Valves VA and VI4 have pneumatic operators controlled from the instrument panel. These valves also may be used to concrol automatically the test section pressure and flow. Excessive steam generated in the test section may be quenched by introducing flow from the 90 gpm pump system into the outlet plenum. This quench flow maintains the required net positive suction head for the pumps to prevent cavitation. Thus, two loops can be in operation simultaneously with independently controlled low, temperature, and pressure.

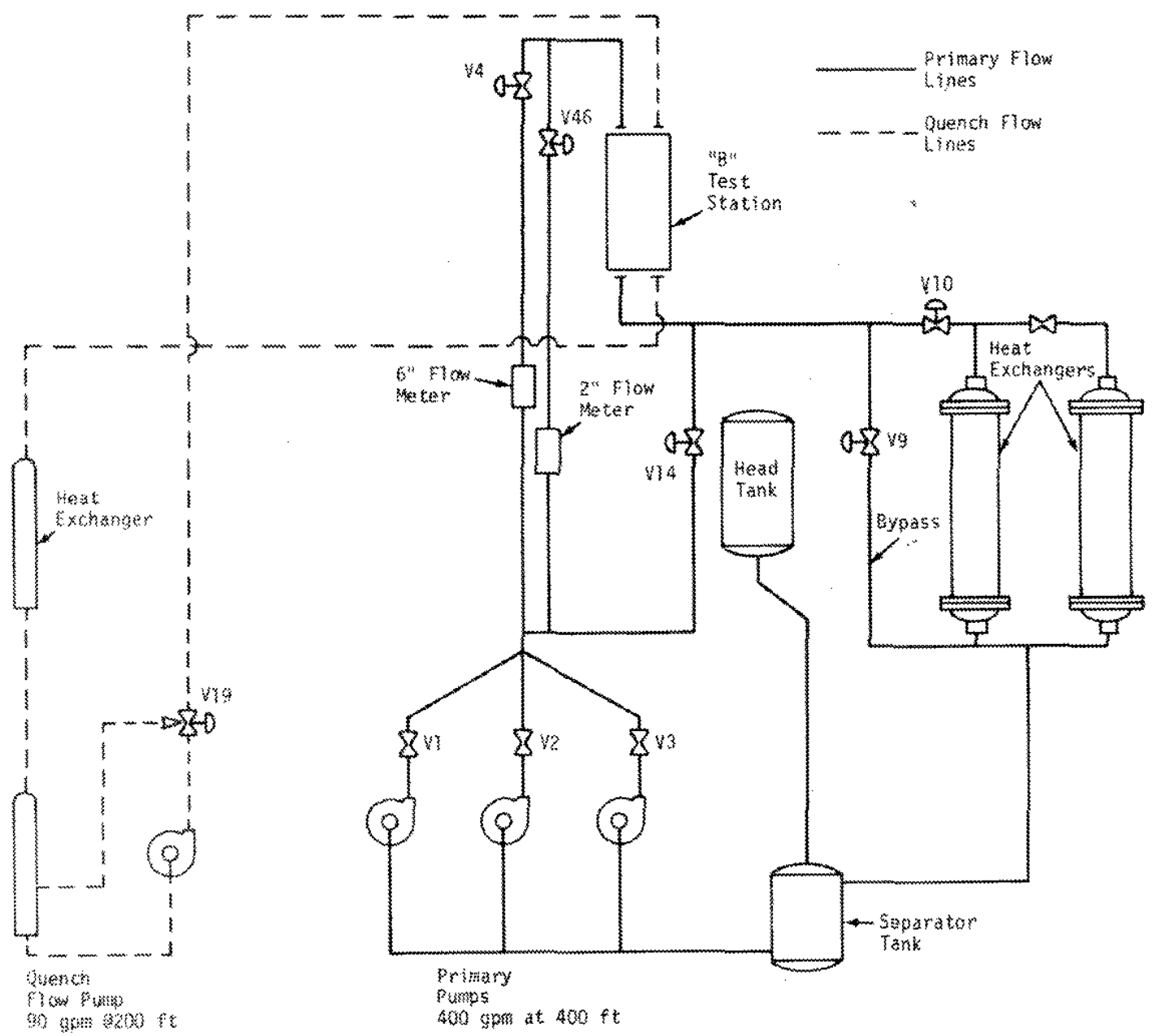

WG. 12. SCHEMATIC OF PIPING TO A SINGLE STATION 
Pritary flow is resurned to the pumps through a large suction header via two heat exchangers arranged in parallel. The how car bypass whe heat exchangers or be partially admitted to the heat oxchangers accoring to temperature control setpoints of the prewatic control valves. Similarly, the quench flow is coolsa by a smallax heat exclanger. The outlet temperature trom this heat exchanger car also be held constant automatically by a controller and bypass valve. Various auxiliary manual valves are located to divert flow from one station to another and to isolate parts of the process system.

process control instrumentation (which excludes special instrumentation associated with a particular test section is avaluble to montor flow, pump suction temperature and pressure, whe pum discharge pressure. Flow is measured by turbine meters in each of the flow loops, as shown in Figure 11 . Four meters awe avaluble depending upon flow loop and flow rate. Nominal accuracy of these meters is within 11 over a range from $10 \%$ to loo ful scale. Flow meters are calibrated by draining water through the meters from the calibration tank. Conductivity level sensors are used to actuate a timer which measures the time required to abcharge an accurately known volume through the meter. Pump discharge prassure is indicated by a Bourdon type 0-300 psi pressume gage. Pump suction pressures axe given by lower range Bourdon gages.

Water in the process loops cones originally from deep weiss on the Savannah River plant site. After filling the loop, the watex is deionized by periodic circulation through mixed bed delonizers. The calbration tank, the surge tank, and to some extent the rest Station Avessel serve as surge suppressors and head tanks tor the pumps. Water level in each tank is indacated by diferential pressure gages on the control panel.

\section{INSTRUMENTATION}

Laboratory instrumentation may be divided generally into two grouys: (1) instrments for process control and (2) instrum ments for acquisition of test data. Within each of these groups the instrumentation is split between recording-type units (e.g., chant recorders) and display type (e.g., Bourdon gages). There is some sharing of function in these divisions, where a process control variable, such as flow, may be used for process control and recorded as test data. As with the hydraulic loops, the instumentation was designed to obtain versatility. Switch panels are provided to allow presentation of incoming signals on selected recording or display devices. In addition, terminats are provided for selecting signals leading to the console displays and feeding them to portable recording instruments. 
Process control instrumentation was described in the preceding section. Electrical power instrumentation was discussed in the description of the rectifiers. Figure 13 is a photograph of the process control console showing digital display meters for monitoring temperatures, pressures, and rectifier power. Pum motor controls, valve controllers, and pressure gages are also shown at the far right. The consoles also contain some of the signa conditioning equipment and jack panels. Figure 14 shows pexwanenty installed recording equipment for slowly changing variables. There are eight chart recorders: foux two pen recorders, one single-pen recorder, and three recorder controllews. Also show in this photograph are the flow meter signa conditioning umits and the rectifier selector panel. Al recorders have a common offmon switch and special event marker triggered by the operator with a button on the main control console.

Portable recording equipment is also available, particularly for taking data involving fast transients. This includes multichanne oscillographic recorders, a digital recordex with up to 80 chamnels capable of recording 20 points per second on magnetic tape, and a high speed digital data acquisition system with 40 chamels for recording up to 30,000 points per second on magnetic tape. An IBM $360 / 195$ located in the Savannah River Laboratory is available for data reduction and analysis. Provision has been made for installation of a remote computer teminal in the heat transfer laboratory building.

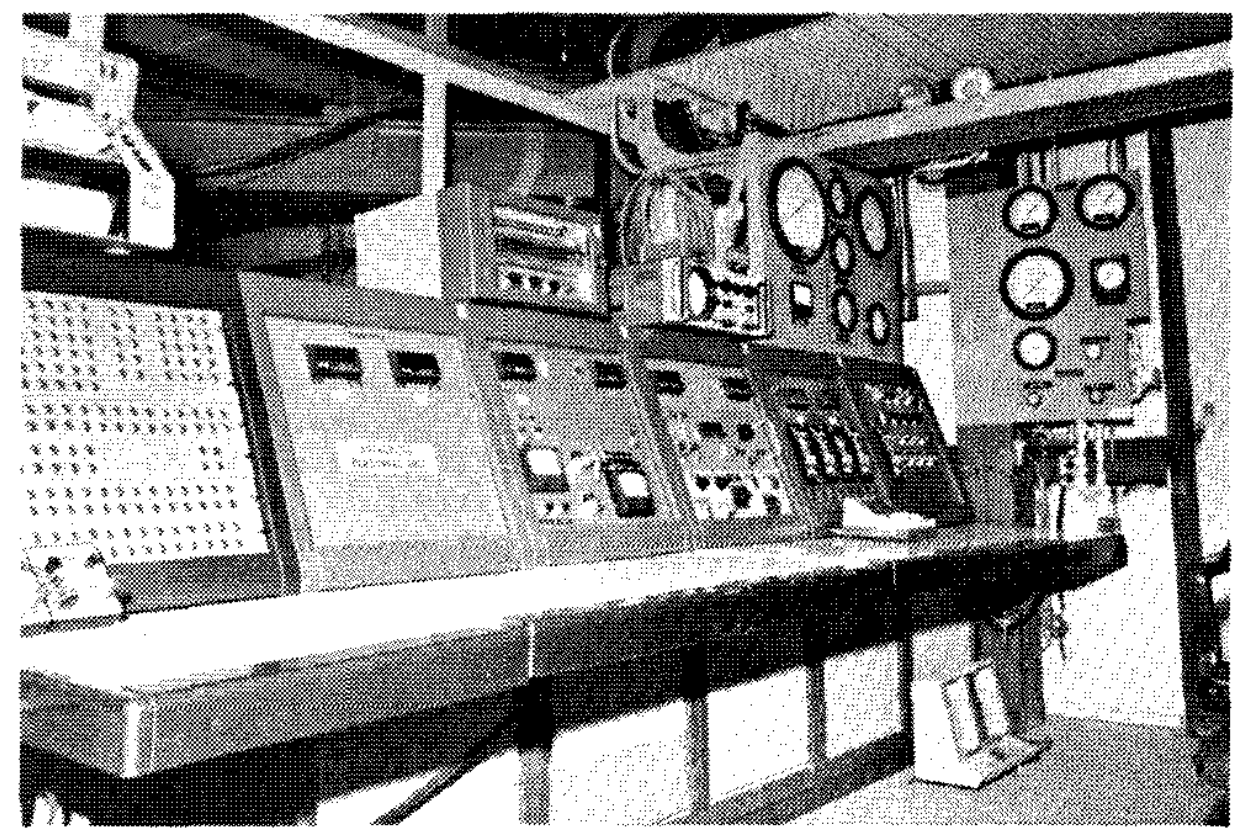

FIG. 13, CONTROL CONSOLE 


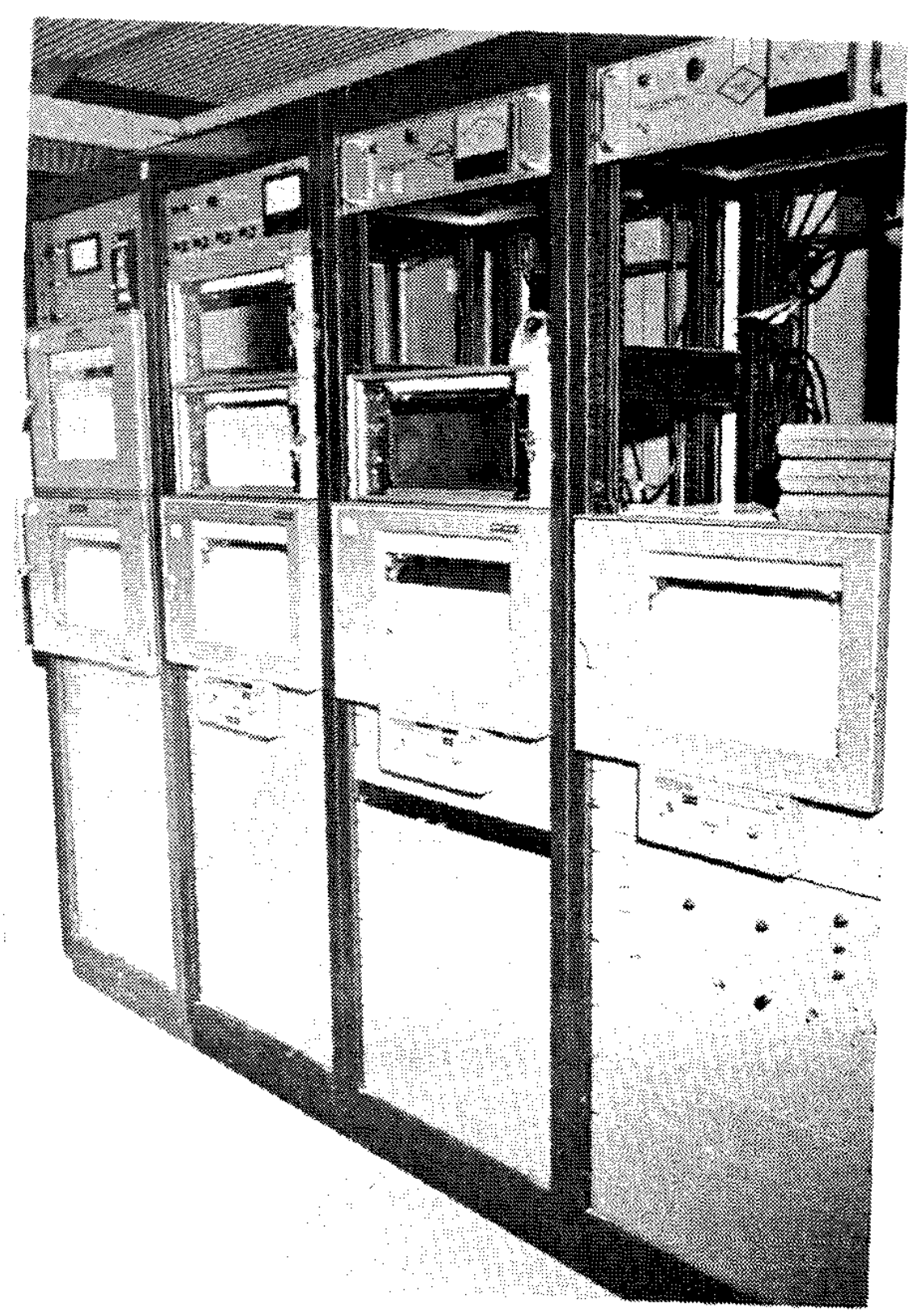

FIG. 14. RECORDER CONSOLE 